\title{
The heat capacity and thermodynamic functions of crystalline and liquid triptycene
}

\author{
JOHN T. S. ANDREWS and EDGAR F. WESTRUM, JR. \\ Department of Chemistry, University of Michigan, Ann Arbor \\ Michigan, 48104, U.S.A.
}

(Received 14 October 1969)

\begin{abstract}
The heat capacity of the propeller-shaped molecule triptycene $\left(\mathrm{C}_{20} \mathrm{H}_{14}\right)$ was measured from 5 to $550 \mathrm{~K}$. No anomaly other than melting was apparent, and the sample ( 99.999 per cent pure, as determined by analysis of the melting curve) melted at $527.18 \mathrm{~K}\left(\Delta_{\mathrm{m}} S=13.73\right.$ cal mol $\left.{ }^{-1} \mathrm{~K}^{-1}\right)$. The crystal density, determined from X-ray measurements, was $1.227 \mathrm{~g}$ $\mathrm{cm}^{-3}$. A comparison of the heat capacity of triptycene with that of bicyclo[2.2.2]octane showed that the two were simply related at low temperatures, but that the comparison was not valid beyond $164.25 \mathrm{~K}$ where bicyclo-octane has a transition to a restricted-rotor phase. The values of $C_{p}, S^{\circ}\left(H^{\circ}-H_{0}^{\circ}\right) / T$, and $-\left(G^{\circ}-H_{0}^{\circ}\right) / T$ for triptycene at $298.15 \mathrm{~K}$ were found to be $67.56,65.48,33.23$, and $-32.25 \mathrm{cal} \mathrm{mol}^{-1} \mathrm{~K}^{-1}$.
\end{abstract}

\section{Introduction}

The hydrocarbon triptycene $\left(\mathrm{C}_{20} \mathrm{H}_{14} ; 9,10\right.$-o-benzeno-9,10-dihydroanthracene $)$ possesses an interesting paddle-wheel structure which was assigned on the basis of chemical, ${ }^{(1)}$ spectroscopic, ${ }^{(2)}$ and n.m.r. ${ }^{(3)}$ evidence. The molecular and crystal structures have been confirmed by X-ray analysis of the $9-\beta$-chloroethyl ${ }^{(4)}$ and $9-$ bromo $^{(5)}$ derivatives of triptycene and of triptycene itself. ${ }^{(6)}$

The hub of the structure is akin to that of bicyclo[2.2.2]octane, ${ }^{(7)}$ the thermodynamic properties of which have been reported elsewhere, ${ }^{(8)}$ in triptycene the cage of bicyclo-octane is augmented by radially disposed benzene rings as shown below.

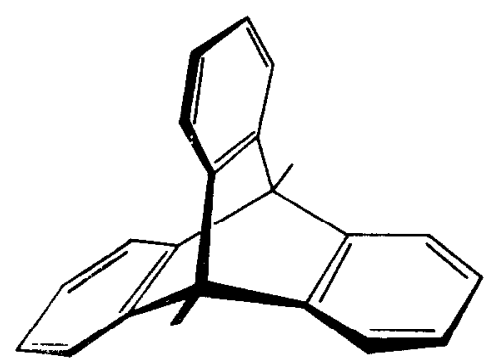

This investigation of the thermal properties of triptycene was undertaken to further our understanding of the thermodynamic properties of molecular crystals composed of symmetrical molecules. It was also hoped that a relationship might be found 
between the heat capacity of triptycene and that of the parent bicyclo-octane. Measurement of the density of the material by X-ray diffraction was used to gain insight regarding the packing within the crystal.

\section{Experimental}

\section{SAMPLE PROVENANCE AND PURIFICATION}

The sample of triptycene obtained from Distillation Products, Inc. consisted of small, white, cubical crystals. The sample was purified by zone-refining techniques: about $120 \mathrm{~g}$ of material was loaded into a Pyrex tube $(13 \mathrm{~mm}$ i.d., $70 \mathrm{~cm}$ long), which was then placed in a vertical array of seven heaters. After slowly raising the tube through a distance equal to the (constant) spacing between the heaters it was then rapidly returned to the starting position. In this way, 693 zones were passed through the sample mass. At the end of the zone-refining, the sample was transparent and colorless save for a 2 to $3 \mathrm{~cm}$ portion at each end of the tube, which was cut off and discarded.

\section{PURITY DETERMINATION}

The purity of the sample was determined from observations of the melting behavior. A plot of the melting temperature against the reciprocal of the fraction melted was analyzed according to the method of Mastrangelo and Dornte, ${ }^{(9)}$ and the results are discussed in detail later in this paper.

\section{SPACE GROUP AND DENSITY DETERMINATION}

A small, well-formed, crystal was chosen from a number grown from the vapor phase, and was mounted on a goniometer. X-ray diffraction photographs were taken of the 0kl, h0l, hK0, 1kl, Hll, and hkl reciprocal lattice nets using a Bucrger precession camera equipped with a Polaroid film holder. Copper $\mathrm{K}_{\alpha}$ radiation was employed, and the dimensions of the unit cell were calculated from direct measurements of the precession photographs.

\section{CALORIMETRY}

The heat capacity of triptycene was determined over two temperature ranges. That from 300 to $550 \mathrm{~K}$ was measured first in the Mark IV intermediate temperature thermostat. ${ }^{(10)}$ The sample was loaded into the high temperature calorimeter by vacuum fusion through a glass frit, which removed any glass chips introduced in the trimming of the zone-melting tube. At the completion of the high temperature measurements, the sample was unloaded by vacuum fusion. Subsequently, it was loaded mechanically into the calorimeter for cryogenic measurements which were made in the Mark II cryostat. ${ }^{(11)}$ Both sets of apparatus employ vacuum techniques to isolate the calorimeter, and use three channels of automatic electronic apparatus (equipped with proportional, rate, and reset action) to control the temperature of the adiabatic shield. The Mark IV thermostat also includes an automatically controlled guard shield. The high temperature calorimeter (laboratory designation W-22N, internal 
volume $83.7 \mathrm{~cm}^{3}$, tare mass including screw closure $94.75 \mathrm{~g}$ ) was of silver; that used for the low temperature measurements was made of gold-plated copper (laboratory designation $\mathrm{W}-42$, internal volume $93.0 \mathrm{~cm}^{3}$, tare mass including screw closure $44.88 \mathrm{~g}$ ). Both calorimeters were equipped with entrant wells into which $25 \Omega$ platinum resistance thermometers were fitted. The heaters were wound on copper sleeves around the thermometers. Thermal contact between the calorimeter and the thermometer-heater assembly was assured by screw pressure (Mark IV), or by use of a small quantity of Apiezon T grease (Mark II). Both calorimeters were sealed with screw closures fitted with gold gaskets. Both platinum resistance thermometers (A-8 in Mark IV, and A-5 in Mark II) had been calibrated by the National Bureau of Standards. All potential differences were measured with a Rubicon six-dial, microvolt, double potentiometer, and all measurements of potential difference, resistance, mass, and time were referred to calibrations or standardizations performed by the National Bureau of Standards.

Heat capacity measurements were made by the quasi-adiabatic technique, ${ }^{(12)}$ corrections being applied for the small departures from adiabatic conditions. The heat capacity of the empty calorimeter together with the thermometer-heater assembly was measured in a separate series of experiments. Small quantities of helium $(0.68 \mathrm{mg}$ for the Mark IV series, $0.76 \mathrm{mg}$ for the Mark II series) were sealed within the calorimeters to assist in the rapid attainment of thermal equilibrium, and corrections were applied for the difference in helium content between the calorimeters when run empty and when run with triptycene.

The calorimetric sample of triptycene had a mass of $70.755 \mathrm{~g}$ for the Mark IV series, and $66.275 \mathrm{~g}$ for the Mark II series. A density of $1.227 \mathrm{~g} \mathrm{~cm}^{-3}$ (obtained from the X-ray measurements) was used to calculate the masses from the weighings.

\section{Results}

\section{HEAT CAPACITY AND THERMODYNAMIC FUNCTIONS}

The heat capacity results are reported in chronological sequence in table 1 . Throughout this paper the molar mass of triptycene, $\mathrm{C}_{20} \mathrm{H}_{14}$, is taken as $254.33 \mathrm{~g} \mathrm{~mol}^{-1}$ (according to the 1961 atomic weights ${ }^{(13)}$ ), cal $=4.184 \mathrm{~J}$, and the ice temperature is taken as $273.15 \mathrm{~K}$. The results have been corrected for the "curvature" occasioned by the finite temperature increments necessarily employed in the heat capacity determinations. ${ }^{(12)}$ These temperature increments may be, in general, inferred from the difference between the mean temperatures of adjacent determinations. Above $50 \mathrm{~K}$ the results are considered to have a probable error of a few hundredths of a per cent. Below this temperature, the results are less precise and 1 per cent may be claimed near $10 \mathrm{~K}$. These estimates are confirmed by comparisons of results taken in these cryostats on standard reference materials ${ }^{(12)}$ with those taken in other laboratories. The heat capacity measurements on triptycene are presented in figure 1 , which combines results from both apparatuses. No thermal anomaly other than that occasioned by fusion is evident in the heat capacity results. Enthalpy Runs A and B covering the temperature interval from 429 to $519 \mathrm{~K}$, agreed within \pm 0.01 per cent with the integral along the smooth curve through the heat capacities. 
TABLE 1. Experimental heat capacity of triptycene

\begin{tabular}{|c|c|c|c|c|c|}
\hline$\frac{T}{\mathrm{~K}}$ & $\frac{C_{\mathrm{p}}}{\mathrm{cal} \mathrm{K}^{-1} \mathrm{~mol}^{-1}}$ & $\frac{T}{\mathrm{~K}}$ & $\frac{C_{p}}{\operatorname{cal} \mathrm{K}^{-1} \mathrm{~mol}^{-1}}$ & $\frac{T}{\mathrm{~K}}$ & $\frac{C_{p}}{\mathrm{cal} \mathrm{K} \mathrm{K}^{-1} \mathrm{~mol}^{-1}}$ \\
\hline \multicolumn{6}{|c|}{ Measurements in the mark IV thermostat } \\
\hline & Series I & 490.26 & 112.07 & 529.22 & 275.4 \\
\hline 295.64 & 66.95 & 497.32 & 113.62 & 533.81 & 130.94 \\
\hline 298.63 & 67.74 & 504.31 & 114.94 & & \\
\hline 305.97 & 69.83 & 507.33 & 115.16 & \multicolumn{2}{|c|}{ Series III } \\
\hline 309.00 & 70.41 & 514.21 & 116.88 & 518.65 & 117.72 \\
\hline 316.49 & 72.49 & 520.92 & 118.26 & 522.06 & 118.51 \\
\hline 325.29 & 74.72 & 525.69 & 268.1 & 525.39 & 123.81 \\
\hline 334.37 & 76.89 & 527.17 & $110 \times 10^{3}$ & 527.08 & 291.2 \\
\hline 343.75 & 79.27 & 527.18 & $160 \times 10^{3}$ & \multicolumn{2}{|c|}{$\Delta_{\mathrm{m}} H$ Run C } \\
\hline 353.43 & 81.62 & 527.18 & $528 \times 10^{3}$ & \multicolumn{2}{|c|}{$\Delta_{\mathrm{m}} H$ Run D } \\
\hline 362.89 & 83.92 & 527.18 & $200 \times 10^{3}$ & 528.59 & 145.47 \\
\hline 372.16 & 85.97 & 527.18 & $100 \times 10^{3}$ & \multirow{2}{*}{\multicolumn{2}{|c|}{ Series IV }} \\
\hline 378.78 & 87.65 & 527.18 & $100 \times 10^{3}$ & & \\
\hline 388.21 & 90.22 & 527.19 & $57 \times 10^{3}$ & 520.07 & 117.77 \\
\hline 397.95 & 92.23 & 528.94 & 234.5 & \multirow{2}{*}{\multicolumn{2}{|c|}{$\Delta_{\mathrm{m}} H$ Run $\mathrm{E}$}} \\
\hline 407.48 & 94.36 & 532.50 & 131.01 & & \\
\hline 416.81 & 96.48 & 536.12 & 131.60 & \multirow{2}{*}{\multicolumn{2}{|c|}{ Series V }} \\
\hline 425.13 & 98.39 & \multirow{2}{*}{\multicolumn{2}{|c|}{ Series II }} & & \\
\hline 432.51 & 99.89 & & & \multicolumn{2}{|c|}{$\Delta_{\mathrm{m}} H$ Run $\mathrm{F}$} \\
\hline 439.81 & 101.50 & \multicolumn{2}{|c|}{ Enthalpy Run A } & \\
\hline 442.99 & 102.13 & \multicolumn{2}{|c|}{ Enthalpy Run B } & & \\
\hline 450.11 & 104.43 & 521.74 & 118.41 & \multicolumn{2}{|c|}{$527.18 \quad \begin{array}{l}\text { Series VI } \\
36 \times 10^{3}\end{array}$} \\
\hline 457.18 & 105.34 & 525.67 & 374.3 & 535.36 & 131.29 \\
\hline 464.14 & 106.84 & 527.18 & $480 \times 10^{3}$ & 538.59 & 131.46 \\
\hline 471.01 & 108.27 & 527.18 & $1100 \times 10^{3}$ & 542.01 & 132.14 \\
\hline 477.51 & 109.62 & 527.18 & $840 \times 10^{3}$ & 545.42 & 132.51 \\
\hline 483.67 & 111.09 & 527.18 & $2600 \times 10^{3}$ & 548.81 & 133.23 \\
\hline \multicolumn{6}{|c|}{ Measurements in the mark Il cryostat } \\
\hline \multicolumn{2}{|c|}{ Series VII } & 129.27 & 28.47 & 15.83 & 2.82 \\
\hline 214.46 & 46.54 & 138.51 & 30.28 & 17.38 & 3.33 \\
\hline 219.35 & 47.96 & 147.88 & 32.14 & 19.12 & 3.98 \\
\hline 226.95 & 49.55 & 157.28 & 34.05 & 21.02 & 4.67 \\
\hline 235.97 & 51.88 & 166.40 & 35.98 & 23.19 & 5.46 \\
\hline 246.14 & 54.36 & 175.46 & 37.92 & 25.79 & 6.36 \\
\hline 255.94 & 56.79 & 184.57 & 39.90 & 28.78 & 7.34 \\
\hline 265.39 & 59.18 & 193.69 & 41.89 & 31.66 & 8.25 \\
\hline 274.53 & 61.46 & 202.86 & 43.99 & 34.71 & 9.18 \\
\hline 283.38 & 63.70 & 212.05 & 46.16 & 38.54 & 10.27 \\
\hline 292.59 & 66.06 & 221.17 & 48.34 & \multirow{2}{*}{\multicolumn{2}{|c|}{ Series $X$}} \\
\hline 302.15 & 68.46 & 230.58 & 50.60 & & \\
\hline 311.43 & 70.84 & 239.87 & 52.91 & 34.93 & 9.24 \\
\hline 320.44 & 73.07 & \multirow{2}{*}{\multicolumn{2}{|c|}{ Series IX }} & 38.95 & 10.37 \\
\hline 330.13 & 75.46 & & & 42.97 & 11.42 \\
\hline 340.45 & 77.97 & 5.71 & 0.12 & 47.34 & 12.53 \\
\hline \multirow{3}{*}{347.34} & 79.46 & 6.56 & 0.20 & 52.03 & 13.64 \\
\hline & & 7.50 & 0.32 & 57.09 & 14.75 \\
\hline & Series VIII & 8.42 & 0.48 & 62.62 & 15.95 \\
\hline 95.11 & 22.12 & 9.41 & 0.74 & 68.77 & 17.18 \\
\hline 102.88 & 23.49 & 10.52 & 1.03 & 75.66 & 18.47 \\
\hline 111.37 & 25.04 & 11.78 & 1.36 & 83.32 & 19.98 \\
\hline 120.24 & 26.73 & 13.17 & 1.80 & 91.69 & 21.52 \\
\hline & & 14.51 & 2.22 & 100.77 & 23.11 \\
\hline
\end{tabular}


THERMODYNAMIC FUNCTIONS OF TRIPTYCENE

TABLE 2. Thermodynamic functions of triptycene

\begin{tabular}{|c|c|c|c|c|}
\hline$\frac{T}{\mathrm{~K}}$ & $\frac{C_{p}}{\text { cal mol } \mathrm{mol}^{-1} \mathrm{~K}^{-1}}$ & 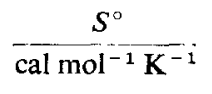 & $\frac{\left(H^{\circ}-H_{0}^{\circ}\right) / T}{\text { cal mol } \mathrm{mol}^{-1} \mathrm{~K}^{-1}}$ & $\frac{-\left(G^{\circ}-H_{0}^{\circ}\right) / T}{\text { cal } \mathrm{mol}^{-1} \mathrm{~K}^{-1}}$ \\
\hline 10 & 0.863 & 0.266 & 2.02 & 0.064 \\
\hline 20 & 4.303 & 1.859 & 26.99 & 0.510 \\
\hline 30 & 7.731 & 4.272 & 87.65 & 1.350 \\
\hline 40 & 10.649 & 6.907 & 179.96 & 2.408 \\
\hline 50 & 13.17 & 9.561 & 299.3 & 3.574 \\
\hline 60 & 15.40 & 12.163 & 442.4 & 4.790 \\
\hline 70 & 17.43 & 14.691 & 606.7 & 6.025 \\
\hline 80 & 19.33 & 17.144 & 790.5 & 7.262 \\
\hline 90 & 21.16 & 19.526 & 993.0 & 8.493 \\
\hline 100 & 22.98 & 21.85 & 1213.8 & 9.712 \\
\hline 110 & 24.81 & 24.13 & 1452.7 & 10.92 \\
\hline 120 & 26.67 & 26.36 & 1710 & 12.11 \\
\hline 130 & 28.58 & 28.57 & 1986 & 13.30 \\
\hline 140 & 30.55 & 30.76 & 2282 & 14.46 \\
\hline 150 & 32.56 & 32.94 & 2597 & 15.62 \\
\hline 160 & 34.63 & 35.11 & 2933 & 16.77 \\
\hline 170 & 36.75 & 37.27 & 3290 & 17.92 \\
\hline 180 & 38.91 & 39.43 & 3668 & 19.05 \\
\hline 190 & 41.12 & 41.59 & 4068 & 20.18 \\
\hline 200 & 43.37 & 43.76 & 4491 & 21.31 \\
\hline 210 & 45.67 & 45.93 & 4936 & 22.43 \\
\hline 220 & 48.01 & 48.11 & 5404 & 23.54 \\
\hline 230 & 50.40 & 50.30 & 5897 & 24.66 \\
\hline 240 & 52.83 & 52.49 & 6413 & 25.77 \\
\hline 250 & 55.29 & 54.70 & 6953 & 26.89 \\
\hline 260 & 57.79 & 56.92 & 7519 & 28.00 \\
\hline 270 & 60.33 & 59.15 & 8109 & 29.11 \\
\hline 273.15 & 61.13 & 59.85 & 8300 & 29.46 \\
\hline 280 & 62.88 & 61.39 & 8725 & 30.22 \\
\hline 290 & 65.46 & 63.63 & 9367 & 31.34 \\
\hline 298.15 & 67.56 & 65.48 & 9909 & 32.25 \\
\hline 300 & 68.03 & 65.90 & 10034 & 32.45 \\
\hline 310 & 70.60 & 68.17 & 10728 & 33.57 \\
\hline 320 & 73.16 & 70.45 & 11446 & 34.68 \\
\hline 330 & 75.70 & 72.74 & 12191 & 35.80 \\
\hline 340 & 78.20 & 75.04 & 12960 & 36.92 \\
\hline 350 & 80.67 & 77.34 & 13755 & 38.05 \\
\hline 400 & 92.53 & 88.90 & 18090 & 43.68 \\
\hline 450 & 103.85 & 100.46 & 23000 & 49.35 \\
\hline 500 & 113.98 & 111.94 & 28453 & 55.03 \\
\hline 527.18 & (119.38) & 118.11 & 31620 & 58.12 \\
\hline \multicolumn{5}{|c|}{ Liquid } \\
\hline 527.18 & $(130.86)$ & 131.84 & 38856 & 58.12 \\
\hline 530 & 130.90 & 132.53 & 39229 & 58.51 \\
\hline 540 & 131.56 & 134.98 & 40541 & 59.90 \\
\hline 550 & 133.45 & 137.41 & 41865 & 61.29 \\
\hline
\end{tabular}




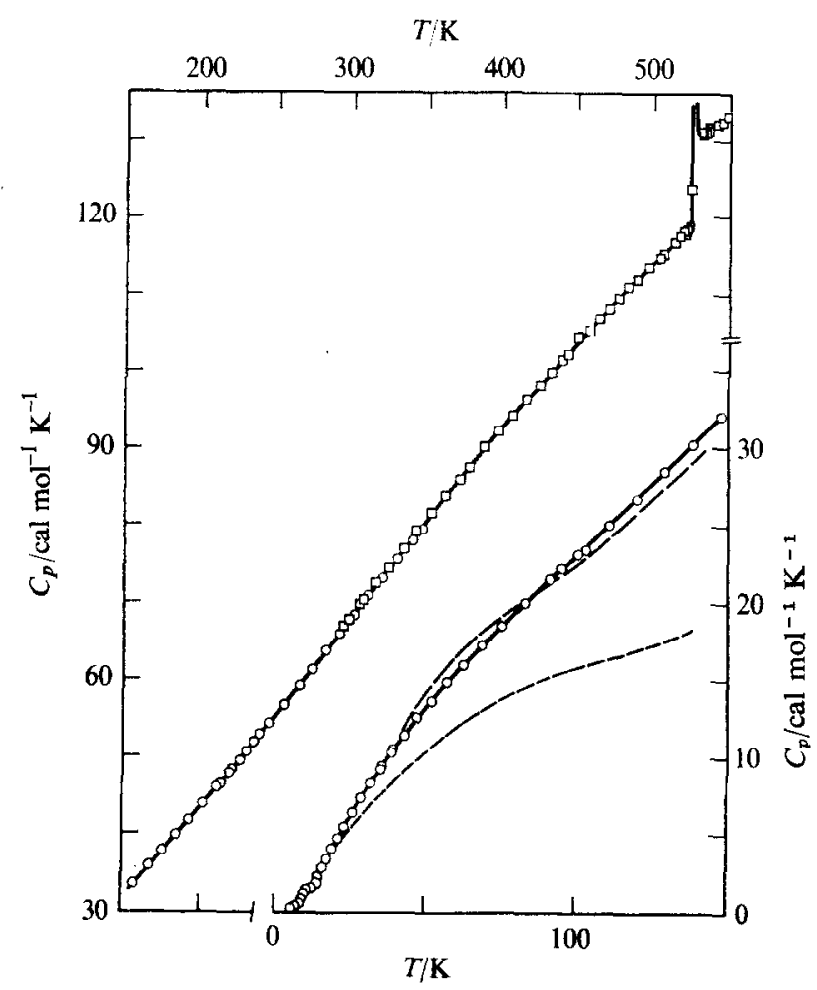

FIGURE 1 . The heat capacity of triptycene. The circles represent the experimental determinations. The dotted curve is the heat capacity of bicyclo[2.2.2]octane. ${ }^{\left({ }^{8}\right)}$ The dashed curve is the latter incremented by three times the $C_{\mathrm{v} 1 \mathrm{~b}}$ of benzene from spectral data ${ }^{(16)}$ and by the hinged motion of the three vanes, and thus represents a model heat capacity in good accord with the results.

The thermodynamic functions of triptycene have been obtained by integration of a polynomial in reduced temperature fitted to the experimental measurements by leastsquares procedures. ${ }^{(14)}$ The resulting functions are considered to have a probable error less than 0.1 per cent above $100 \mathrm{~K}$. They are presented in table 2, together with the heat capacity at rounded temperatures obtained by the expansion of the polynomial.

The extrapolation of the heat capacity below the lowest temperature of the measurements was accomplished with the aid of a $C_{p} / T$ against $T^{2}$ plot. ${ }^{(12)}$ The linearity of this plot indicated that the Debye $T^{3}$ law holds well for this material.

\section{THERMODYNAMICS OF MELTING}

The enthalpy of melting $\Delta_{\mathrm{m}} H$ was measured in five series of determinations through the melting region. The apparent enthalpy increments were corrected for the lattice (or background) heat capacities of the liquid and crystal phases by the use of linear extrapolations fitted by least-squares to the heat capacities below and above the melting temperature. The enthalpy changes were also corrected for the departure from adiabatic conditions over the duration of long determinations from a knowledge of 
the temperature drift and the average heat capacity of the sample. These drift corrections were required only on those sequences which consisted of many small energy inputs, or if a long wait was needed before thermal equilibration was reached. Of the five series, two required large drift corrections, and were therefore excluded from the averaging procedure. The remaining three sequences required only very small corrections.

A summary of the determinations of the melting enthalpy is made in table $3 . \Delta_{\mathrm{m}} S$ was determined by assuming that melting is truly isothermal. In view of the absence of premelting, this is a defensible procedure.

The apparent melting temperature varied as a function of the fraction $f$ of the sample melted (see table 4). A plot of the melting temperature against the reciprocal

TABLE 3. Enthalpy of fusion of triptycene

\begin{tabular}{|c|c|c|c|c|c|}
\hline $\begin{array}{l}\text { Series and } \\
\text { designation }\end{array}$ & $\begin{array}{l}T_{1} \\
\ddot{\mathbf{K}}\end{array}$ & $\frac{T_{2}}{\bar{K}}$ & $\frac{H\left(T_{1}\right)-H\left(T_{2}\right)}{\mathrm{cal} \mathrm{mol}}$ & $\frac{\Delta H(\text { lattice })}{\text { cal mol }}$ & $\frac{\Delta_{\mathrm{m}} H^{a}}{\text { cal mol-1 }}$ \\
\hline $\begin{array}{l}\text { 1, Points } 32 \text { to } 41 \\
3, \Delta_{\mathrm{m}} H \text { Runs } \mathrm{C} \text { and } \mathrm{D} \\
\text { 4, } \Delta_{\mathrm{m}} H \text { Run } \mathrm{E} \\
5, \Delta_{\mathrm{m}} H \text { Run } \mathrm{F}\end{array}$ & $\begin{array}{l}517.62 \\
520.36 \\
516.42 \\
522.68\end{array}$ & $\begin{array}{l}530.70 \\
530.01 \\
537.19 \\
536.55\end{array}$ & $\begin{array}{l}8830.8 \\
8422.9 \\
9820.3 \\
8998.0\end{array}$ & $\begin{array}{l}1592 \\
1180 \\
2584 \\
1762\end{array}$ & $\begin{array}{l}7240^{\circ} \\
7236 \\
7236 \\
7236\end{array}$ \\
\hline $\begin{array}{l}T_{\mathrm{m}} / \mathrm{K}=527.18 \\
\Delta_{\mathrm{m}} S / \mathrm{cal} \mathrm{mol} \mathrm{mol}^{-1} \mathrm{~K}^{-1}=13.73\end{array}$ & & & & \multicolumn{2}{|c|}{ Average $\Delta_{\mathrm{m}} H: 7236$} \\
\hline
\end{tabular}

a Corrected for "lattice" enthalpy increments between $T_{1}$ and $T_{\mathrm{m}}, T_{\mathrm{m}}$ and $T_{2}$, and for quasiadiabatic drifts.

${ }^{b}$ Excluded from the average as thermal equilibrium was not awaited during this series.

of the fraction melted was linear at larger values of $1 / f$, but showed significant upward curvature at lower values indicative of solid solution formation between the pure material and its impurity. Analysis of this curve by the method of Mastrangelo and Dornte ${ }^{(9)}$ shows that the sample was 99.999 moles per cent pure and that the distribution coefficient of the impurity between solid and liquid phases was 0.637 .

TABLE 4. Fractional melting of triptycene

\begin{tabular}{|c|c|c|c|c|c|}
\hline$\frac{\langle T\rangle}{K}$ & $\frac{C_{p}}{\text { cal mol } \mathrm{mol}^{-1}} \overline{\mathrm{K}^{-1}}$ & $\frac{\Delta H}{\mathrm{cal} \mathrm{mol}^{-1}}$ & $\frac{\Delta H_{\text {excess }}}{\mathrm{cal} \mathrm{\textrm {mol } ^ { - 1 }}}$ & $f^{-1}$ & $\frac{T_{\text {tnal }}}{\mathrm{K}}$ \\
\hline 525.67 & 374.28 & 1125.36 & 766.96 & 9.43 & 527.1745 \\
\hline 527.18 & $480 \times 10^{3}$ & 1086.16 & 1085.89 & 3.91 & $\$ 27.1767$ \\
\hline 527.18 & $1150 \times 10^{3}$ & 1880.31 & 1880.11 & 1.94 & 527.1784 \\
\hline 527.18 & $840 \times 10^{3}$ & 1489.08 & 1488.86 & 1.39 & 527.1802 \\
\hline 527.18 & $2600 \times 10^{3}$ & 1487.18 & 1487.18 & 1.08 & 527.1807 \\
\hline \multirow[t]{2}{*}{529.22} & 275.41 & 1125.52 & 590.19 & & \\
\hline & \multicolumn{5}{|c|}{$\Sigma \Delta H_{\text {oxcess }}=7236.2$} \\
\hline
\end{tabular}

Triple point of sample: $T_{\mathrm{m}} / \mathrm{K}=527.181$; triple point of pure compound: $T_{\mathrm{m}}^{\circ} / \mathrm{K}=527.184$. Mole fraction of impurity: $5 \times 10^{-6}$ by method of Mastrangelo and Dornte. ${ }^{(9)}$ 


\section{SPACE GROUP AND DENSITY OF THE CRYSTAL}

Examination of the reciprocal lattice nets obtained with the precession camera showed that three point groups had to be considered: $m m m, m m 2,222$. The crystal was therefore orthorhombic. No general absences were to be seen, but special absences of the type $h 00,0 \mathrm{k} 0,001$ were seen where $h, k, l$ were odd. These absences are those due to three $2_{1}$ screw axes parallel to the crystal axes, and the space group may therefore be unambiguously determined as $P 2_{1} 2_{1} 2_{1}$. This space group has four general positions in the unit cell ${ }^{(15)}$ which do not have special symmetry (point symmetry 1 ). Since the unit cell contains four formula units (as determined from molecular weight and cell volume), it is not possible to draw any conclusions as to the molecular symmetry from the space group. Measurement of the reciprocal lattice parameters shows that the dimensions of the unit cell are $0.826,2.055$, and $0.811 \mathrm{~nm}$. For four formula units per cell, the density is $1.227 \mathrm{~g} \mathrm{~cm}^{-3}$. This crystallographic information is in good agreement with unpublished X-ray data of Neuman and Knox ${ }^{(6)}$ and the apparent density in the zone melting tube.

\section{Discussion}

The similarities between the molecular structures of triptycene and bicyclo-octane encouraged attempts to relate the heat capacity of these two compounds. The molecule of triptycene may be regarded as a central hub of bicyclo-octane around which three benzene rings are arranged somewhat like the vanes (or blades) of a paddle wheel. This model obviously introduces some atoms and bonds that are not present in the molecule of triptycene and the comparison ought not to be carried to high temperatures where these "extra" components contribute significantly to the heat capacity. At low temperatures, however, the vibrations associated with these groups should not be greatly excited, and comparison may be attempted. The contributions of the benzene rings to the heat capacity are occasioned by the internal vibration of the benzene molecule and the bending motions of the rigid vanes with respect to the hub. The first contribution may be calculated from the vibrational frequency assignment of Calloman, Dunn, and Mills; ; $^{(16)}$ the second, from the bending modes, might be estimated by comparison with the as yet unknown bending mode in dihydroanthracene.

Figure 1 demonstrates the applicability of this model. Here, the heat capacity of bicyclo-octane $^{(8)}$ plus three times the vibrational heat capacity of benzene ${ }^{(16)}$ is taken to represent all contributions for the model except that from the bending modes. The difference between this sum and the heat capacity of triptycene is related to the heat capacity of the bending mode and may be represented by three Einstein terms with characteristic temperatures of $144 \mathrm{~K}\left(\cong 100 \mathrm{~cm}^{-1}\right)$. This implies that the wavenumber of the normal mode best describing this bending lies at $100 \mathrm{~cm}^{-1}$. In the absence of experimental results, calculated force constants for. this mode are in substantial accord with force constants for similar bending listed by Herzberg. ${ }^{(17)}$ The model shows good agreement with the heat capacity of triptycene until bicyclo-octane undergoes transition to a restricted-rotor phase at $164.25 \mathrm{~K}$. Triptycene, however, is tightly packed into the lattice and is apparently unable to reorient. This model of the behavior of triptycene appears to have validity at low temperatures, but at higher 
temperatures it is likely that the "extra" bonds and atoms introduced contribute to the heat capacity.

The difference in heat capacity between the crystal and liquid phases may be calculated (from the intercepts at the melting temperature of the linear extrapolations fitted to the data above and below this temperature) as $11.48 \mathrm{cal} \mathrm{mol}^{-1} \mathrm{~K}^{1}$ or $5.8 R$. This large difference suggests that the molecules are held rigidly in the crystal lattice, and acquire significant motion only upon passing into the liquid phase.

If the molecules, rigidly held in the lattice, acquire free rotational and translational ability on melting, then the new motions will add $R / 2$ for each degree of freedom of the motion, or $3 R$ in all. Restricted motions can add up to $R$ for each degree of freedom, or $6 R$ in all. The experimental heat capacity difference, $5.8 R$, suggests that the motions of the molecules in the liquid immediately above the melting point are restricted. Al Mahdi and Ubbelohde ${ }^{(18)}$ concluded (from volumetric studies) that this must be the case for many organic molecules.

The authors are grateful to the Division of Research of the United States Atomic Energy Commission for support of the research endeavor. One of us (J. T. S. A.) thanks the University of Michigan for Rackham Predoctoral Fellowships.

\section{REFERENCFS}

1. Clar, E. Chem. Ber. 1931, 64, 1676.

2. Bartlett, P. D.; Greene, F. D. J. Amer. Chem. Soc. 1954, 76, 1088.

3. Theilacker, W.; Albrecht, K.; Uffman, H. Chem. Ber. 1965, 98, 428.

4. Estlin, J. A.; Karle, I. L. Paper F-4, Abstracts of the Winter Meeting of the American Crystallographic Association, at Atlanta, Georgia, January 1967.

5. Palmer, K. J.; Templeton, D. H. Acta Cryst. 1968, B24, 1048.

6. Neuman, M. A.; Knox, K. Addendum to the Abstracts of the Annual Meeting of the American Crystallographic Association, Minneapolis, Minnesota, August 1967.

7. Bauer, J. Sb. Vysoke Skoly Chem.-Technol. v Praze, Oddil Fak. Anorg. Org. Technol. 1957, 145.

8. Wong, W.-K. Ph.D. Thesis, The University of Michigan, Ann Arbor, Michigan. 1966.

9. Mastrangelo, S. V. R.; Dornte, R. W. J. Amer. Chem. Soc. 1955, 77, 6200.

10. West, E. D.; Westrum, E. F., Jr. Adiabatic calorimetry from 300 to $800 \mathrm{~K}$, in Experimental Thermodynamics, Vol. 1. McCullough, J. P.; Scott, D. W. : editors. Butterworths: London. 1968.

11. Westrum, E. F., Jr. Application of cryogenic calorimetry to solid state chemistry, in Advances in Cryogenic Engineering, Vol. 7. Timmerhaus, K. D.: editor. Plenum Press: New York. 1962.

12. Westrum, E. F., Jr.; Furukawa, G. T.; McCullough, J. P. Adiabatic low-temperature calorimetry, in Experimental Thermodynamics, Vol. 1. McCullough, J. P.; Scott, D. W.: editors. Butterworths: London. 1968.

13. Cameron, A. E.; Wichers, E. J. Amer. Chem. Soc. 1962, 84, 4175.

14. Justice, B. H. Ph.D. Thesis, The University of Michigan, Ann Arbor, Michigan. 1961; USAEC Rept. TID 127221961.

15. International Tables for X-ray Crystallography, Vol. I. Henry, Norman F. M.; Lonsdale, Kathleen: editors. Kynoch Press: Birmingham. 1952.

16. Calloman, J. H.; Dunn, T. M.; Mills, I. M. Phil. Trans. Roy. Soc. 1966A, 259, 499.

17. Herzberg, G. Infrared and Raman Spectra of Polyatomic Molecules. Van Nostrand: New York. 1945, p. 195.

18. Al Mahdi, A. A. K.; Ubbelohde, A. R. Proc. Roy. Soc. A 1953, 220, 143. 